\title{
Auxins, Salt Concentrations, and Their Interactions during in Vitro Rooting of Winter-hardy and Hybrid Tea Roses
}

\author{
Neville P. Arnold, Michael R. Binns ${ }^{1}$, Daniel C. Cloutier, \\ Nayana N. Barthakur ${ }^{2}$, and Raymond Pellerin ${ }^{3}$ \\ Agriculture Canada, Research Branch, Experimental Farm, P.O. Box 3398, \\ 801 Route 344, L'Assomption, Que. J0K 1G0, Canada
}

Additional index words. Rosa hybrida, Rosa kordesii, tissue culture, nutrient media

\begin{abstract}
Auxins, medium salt concentrations, and their interactive effects on rooting of two winter-hardy roses (Rosa kordesii Wulff 'John Franklin' and 'Champlain') and two hybrid teas (Rosa hybrida 'John Paul II' and 'Landora') were studied. The auxins (in mg.liter $\left.^{-1}\right)$ IAA $(0,0.3,1.5,3.0,6.0$, or 15.0), IBA $(0,0.1,0.2,0.5,1.0$, or 3.0 $)$, and NAA $(0$, $0.1,0.2,0.5,1.0$, or 3.0) each were combined factorially with modified Murashige and Skoog (MS) medium (1/4, 1/2,3/4, and full MS concentrations) and were tested for optimal rooting response. 'John Franklin', 'John Paul II', and 'Landora' rooted well with low or no auxin and medium to high salt concentrations. Optimum rooting for 'Champlain' was achieved with high IAA and low salts or with intermediate IBA and NAA concentrations and low to medium salts. The interactive effects of auxins and medium salts for 'Champlain' showed that as salt concentration increased, the amount of IBA or NAA required for optimal rooting also increased. The effects of auxins and medium concentrations on root counts per shoot were similar to those for percent rooting. Adding auxin to the medium reduced root length for all cultivars, but salt concentration had a minimal effect. Roots generally were shortest at the highest IBA and NAA concentrations. Salt concentration had little effect on root length. Chemical names used: $1 H$-indole-3-acetic acid (IAA); 4-(3indolyl)-butyric acid (IBA); $\alpha$-naphthaleneacetic acid (NAA).
\end{abstract}

Rooting success of in vitro-cultured rose plantlets depends on auxin, salt content, or a combination of both (Davies, 1980; Hasegawa, 1980; Hyndman et al., 1982; Khosh-Khui and Sink, 1982; Skirvin and Chu, 1979). The auxins IAA and NAA, but not IBA, stimulated rooting for $>80 \%$ of plantlets in 'Bridal Pink' roses (Kosh-Khui and Sink, 1982); IAA was slightly more effective than NAA. NAA and IBA stimulated root initiation of 'Improved Blaze' at concentrations $<0.10$ and 1.0 mg.liter ${ }^{-1}$, respectively. IAA induced good rooting but at 10-times the NAA concentration needed (Hasegawa, 1980). NAA plus IBA or IAA increased rooting more than IAA, IBA, or NAA alone (Khosh-Khui and Sink, 1982). Although Valles and Boxus (1987) reported differences in hormonal requirements for rooting rose cultivars, in vitro-proliferated shoots cultured on a basal medium without growth regulators also initiated roots successfully (Hasegawa, 1980; Skirvin and Chu, 1979).

Received for publication 2 Aug. 1994. Accepted for publication 2 July 1995 . The cost of publishing this paper was defrayed in part by the payment of page charges. Under postal regulations, this paper therefore must be hereby marked advertisement solely to indicate this fact.

${ }^{1}$ Research Scientist. Current address: Agriculture Canada, Research Branch, Central Experimental Farm, Ottawa, Ont. K1A 0C6, Canada.

${ }^{2}$ Professor of Agricultural Physics. Current address: Dept. of Natural Resource Sciences, Macdonald Campus-McGill Univ., 21,111 Lakeshore Rd., SteAnne-de-Bellevue, Que. H9X 3V9, Canada.

${ }^{3}$ Research Technician.
Relatively low salt concentrations in the medium can enhance rooting of plantlets in vitro (Murashige, 1979). Root initiation increased significantly for 'Improved Blaze' roses when the salt concentration of the medium was low (Hyndman et al., 1982). The authors attributed this increased rooting to a low $\mathrm{N}$ concentration. A reduction in medium salt content combined with NAA (Skirvin et al., 1984), or a combination of auxins (KhoshKhui and Sink, 1982), promoted good rooting; $>90 \%$ of 'Improved Blaze' shoots developed roots when NAA or IAA was combined with $1 / 4$ to $1 / 2$ concentrations of MS medium. However, the auxins $\times$ salt concentration interaction in the medium has not been examined fully.

Our objective was to determine the type and concentration of auxin, nutrient concentration in the medium, and their interactive effects on optimal rooting of two winter-hardy and two hybrid tea roses.

\section{Materials and Methods}

We used cultured shoots of winter-hardy shrub roses ('Champlain' and 'John Franklin') and hybrid tea roses ('John Paul II' and 'Landora'). Shoots $\approx 15 \mathrm{~mm}$ long were transferred into $25 \times 150$-mm culture tubes (single experimental units in which treatments were applied) containing $10 \mathrm{ml}$ of MS medium, modified to contain 3/4 concentration of macronutrients; $\mathrm{NH}_{4} \mathrm{NO}_{3}$ adjusted to 1856 mg.liter ${ }^{-1}$; and full concentration of micronutrients, with $\mathrm{ZnSO}_{4} 7 \mathrm{H}_{2} \mathrm{O}$ and $\mathrm{MnSO}_{4} \mathrm{H}_{2} \mathrm{O}$ altered to 21.2 and $33.8 \mathrm{mg} \cdot$ liter $^{-1}$, respec- tively (Arnold et al., 1992). Sucrose (3\%) and Phytagar (0.6\%) (Gibco Laboratories, Grand Island, N.Y.) were added to the medium, and $\mathrm{pH}$ was calibrated to $5.7 \pm 0.1$ with $0.25 \mathrm{~N}$ $\mathrm{NaOH}$ before autoclave sterilization at $121 \mathrm{C}$ for $15 \mathrm{~min}$.

Experiments were conducted to test the effect of auxins, salt concentrations in the medium, and their interactions on rooting. The auxins (in mg.liter $\left.{ }^{-1}\right)$ IAA $(0,0.2,0.3,3.0,6.0$, or 15$)$, IBA $(0,0.1,0.2,0.5,1.0$, or 3$)$, and NAA $(0,0.1,0.2,0.5,1.0$, or 3$)$ each were combined factorially with modified MS medium at 1/4,1/2, 3/4, and full concentrations. Treatments in each experiment were arranged in a randomized complete-block design with 10 replications. Explants were incubated for 4 weeks at $25 \mathrm{C}$ under a 16 -h photoperiod (30 to $40 \mu \mathrm{mol} \cdot \mathrm{m}^{-2} \cdot \mathrm{s}^{-1}$ ) provided by cool-white fluorescent tubes (Sylvania, Montréal, Que., Canada).

Data on number of roots, mean root length per explant, and means of shoot explants developing roots were recorded. Because data distribution deviated from normal, the analysis of deviance (McCullagh and Nelder, 1983) was used, instead of the analysis of variance, to determine treatment effects and provide SE of means. We made the following assumptions in our analyses: percent rooting (binomial), number of roots (Poisson), and length of roots (gamma) distributions. For these distributions, the size of the SE of a mean depends on the mean value itself. However, to simplify tables and figures, only average sEs or maximum and minimum sEs are presented. Plant characteristics were plotted linearly along the ordinates vs. natural logarithms of $1+$ auxin concentrations, which enabled us to use the zero auxin concentration on positive abscissa. All analyses were performed using a Genstat (1987) statistical package.

\section{Results}

'Champlain'. The medium salt (M) $\times$ IAA concentrations $\left(\mathrm{C}_{\mathrm{A}}\right)$ interaction was not significant for percent rooting and root counts but was significant $(P \leq 0.05)$ for average root length (Table 1). Rooting increased toward $100 \%$ with increased $\ln \mathrm{C}_{\mathrm{A}}$ except at $\mathrm{M}=1$, which depressed rooting (Fig. 1). The number of roots per plant increased with increased $l n$ $\mathrm{C}_{\mathrm{A}}$ for all $\mathrm{M}$ (Fig. 2). The average root length decreased sharply for $\ln C_{A} \leq 0.3 \mathrm{mg} \cdot \operatorname{liter}^{-1}$ and then remained almost constant when $\mathrm{C}_{\mathrm{A}}$ was increased further (Fig. 3).

The IBA concentration $\left(\mathrm{C}_{\mathrm{B}}\right) \times \mathrm{M}$ interaction was highly significant $(P \leq 0.01)$ for the characteristics studied (Table 1). Rooting increased rapidly toward $100 \%$ until $\ln C_{B}=0.4$ $\mathrm{mg} \cdot \mathrm{liter}^{-1}$, after which rooting percentage either remained constant or decreased depending on $\mathrm{M}$ (Fig. 1). Rooting percentage reached zero for $M=1 / 4$ at the highest $\ln C_{B}$. The behavior was similar for number of roots (Fig. 2). The number of roots remained at eight for $M=3 / 4$ and 1 with increased $\ln C_{B}$. The average root length decreased sharply until 0.3 $\mathrm{mg}$ IBA/liter, then decreased gradually with further increase in $C_{B}$ (Fig. 3). 
Significant $(P \leq 0.01)$ NAA concentration $\left(\mathrm{C}_{\mathrm{N}}\right) \times \mathrm{M}$ interactions occurred for percent rooting and the number of roots $(P \leq 0.05)$, but not for the average root length (Table 1). Rooting percentage increased rapidly at first and attained a maximum value, after which rooting decreased as $\ln \mathrm{C}_{\mathrm{N}}$ increased for all $\mathrm{M}$ (Fig. 1). The number of roots increased and reached a maximum of eight at $\ln \mathrm{C}_{\mathrm{N}}=0.8$ mg. liter ${ }^{-1}$ and then decreased toward zero for $M=3 / 4$. Root counts increased for $\ln C_{N}=0.8$ mg.liter ${ }^{-1}$, and it remained constant at two for $M=1 / 4$ and four at $M=3 / 4$ and 1 . The fewest roots resulted from $M=1 / 4$ (Fig. 2). The average root length decreased with increased $\ln \mathrm{C}_{\mathrm{N}}$, regardless of $\mathrm{M}$ (Fig. 3).
'John Franklin'. The $\mathrm{C}_{\mathrm{A}} \times \mathrm{M}$ interaction was significant $(P \leq 0.05)$ for percent rooting but was not significant for number of roots and average root length (Table 1). Rooting percentage remained constant with increased $\ln$ $\mathrm{C}_{\mathrm{A}} ; 100 \%$ rooting occurred at $\mathrm{M}=3 / 4$ and 1 (Fig. 1). Only $\approx 70 \%$ of cuttings rooted at $\mathrm{M}=$ $1 / 4$, and root counts behaved similarly (Fig. 2).

Table 1: Analyses of deviance for the effects of medium and auxin concentrations and their interaction on percent rooting, number of roots, and average root length of winter-hardy and hybrid tea rose cultivars.

\begin{tabular}{|c|c|c|c|c|c|c|c|c|c|c|c|c|}
\hline \multirow[b]{3}{*}{ Variable } & \multicolumn{12}{|c|}{ Cultivar } \\
\hline & \multicolumn{3}{|c|}{ Champlain $^{z}$} & \multicolumn{3}{|c|}{ John Franklin ${ }^{2}$} & \multicolumn{3}{|c|}{ John Paul II ${ }^{y}$} & \multicolumn{3}{|c|}{ Landora $^{y}$} \\
\hline & IAA & IBA & NAA & IAA & IBA & NAA & IAA & IBA & NAA & IAA & IBA & NAA \\
\hline \multicolumn{13}{|c|}{ Percent rooting } \\
\hline Medium salt strength (M) & NS & NS & NS & ** & ** & ** & $* *$ & ** & $* *$ & * & NS & NS \\
\hline Auxin conen $(\mathrm{C})$ & NS & ** & ** & NS & $* *$ & ** & $* *$ & $* *$ & ** & NS & $* *$ & ** \\
\hline $\mathrm{M} \times \mathrm{C}$ & NS & $* *$ & $* *$ & $*$ & NS & $*$ & NS & NS & $* *$ & NS & NS & NS \\
\hline \multicolumn{13}{|c|}{ No. roots } \\
\hline M & ** & $* *$ & NS & ** & ** & ** & ** & $* *$ & ** & ** & ** & NS \\
\hline $\mathrm{C}$ & $* *$ & ** & ** & NS & ** & ** & NS & $* *$ & ** & * & $* *$ & ** \\
\hline $\mathrm{M} \times \mathrm{C}$ & NS & $* *$ & $*$ & NS & $*$ & NS & $*$ & $* *$ & $* *$ & NS & $* *$ & NS \\
\hline \multicolumn{13}{|c|}{ Avg root length } \\
\hline M & NS & $* *$ & NS & $* *$ & NS & ** & $*$ & NS & NS & NS & NS & $* *$ \\
\hline $\mathrm{C}$ & $* *$ & $* *$ & ** & ** & $* *$ & ** & $* *$ & ** & ** & ** & ** & $*$ \\
\hline $\mathrm{M} \times \mathrm{C}$ & $*$ & $* *$ & NS & NS & $*$ & NS & $*$ & NS & NS & NS & $* *$ & $*$ \\
\hline
\end{tabular}

${ }^{2}$ Winter hardy.

${ }^{y}$ Hybrid tea.

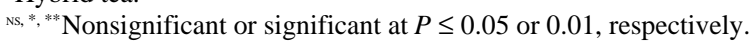

Champlein

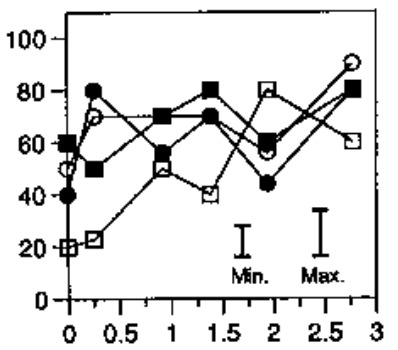

John Franklin

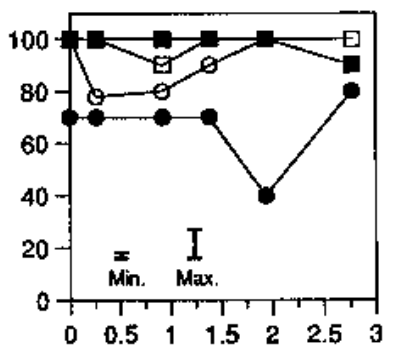

John Paul II
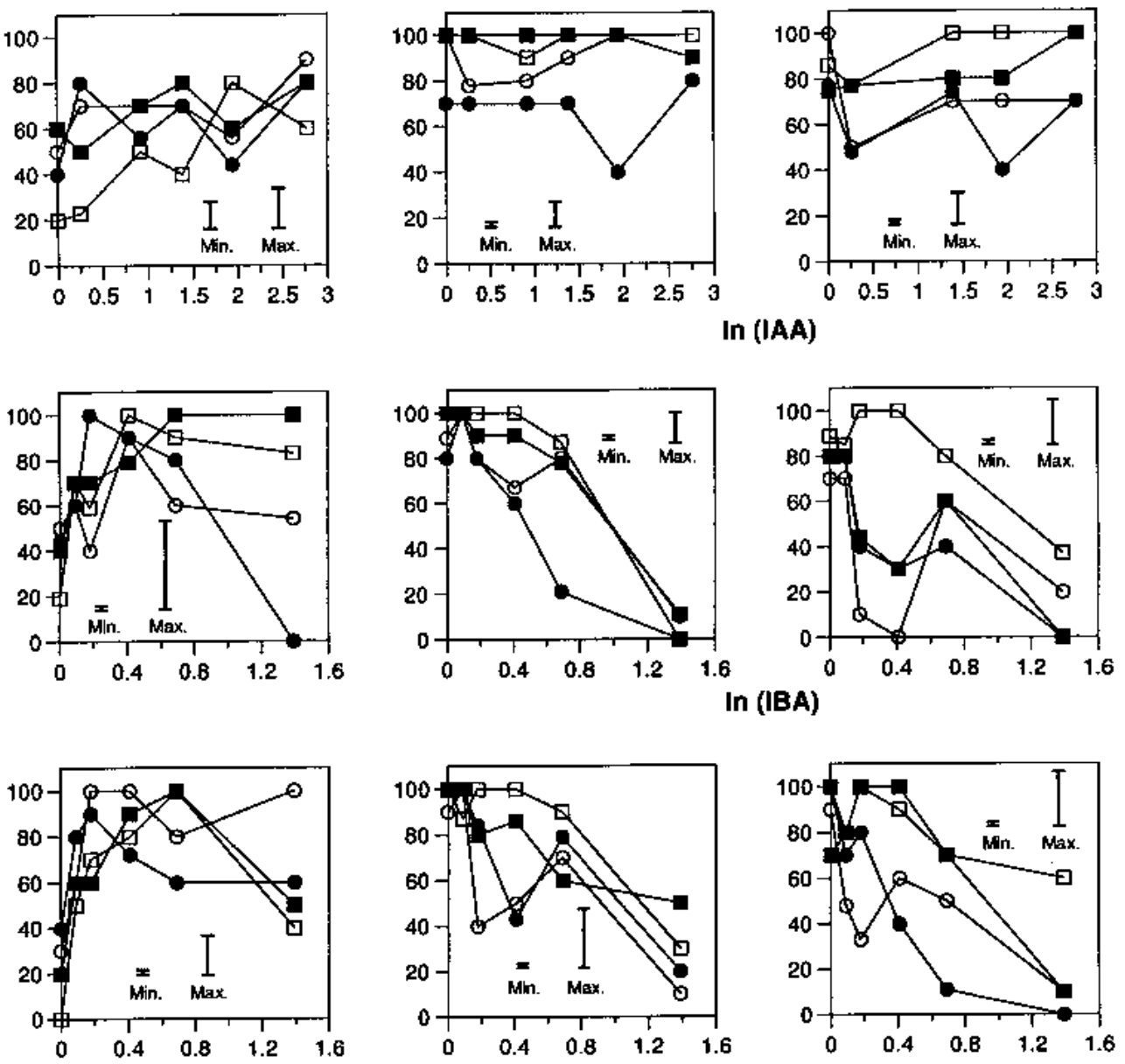

In (IBA)
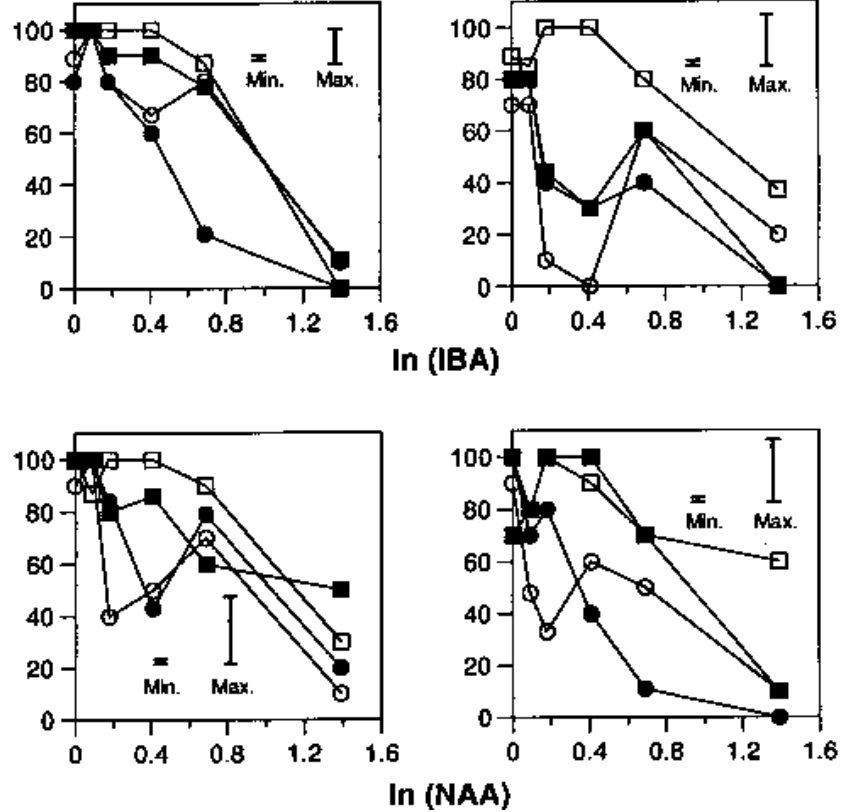

Landora
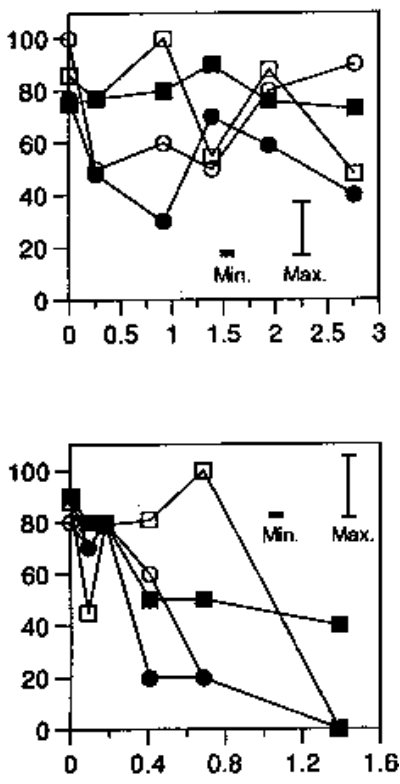

Fig. 1. Influence of auxins and medium concentrations $[(-) 1 / 4,(\bigcirc) 1 / 2,(\square) 3 / 4$, and (অ) 1] on percent rooting of two hardy and two hybrid tea roses. Abscissa represent natural logarithms of $(1+$ auxin concentrations). Minimum and maximum ses of a mean are shown. 
Champlein

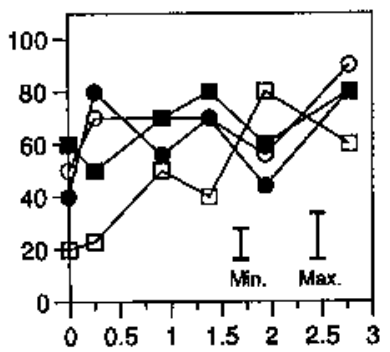

John Franklin

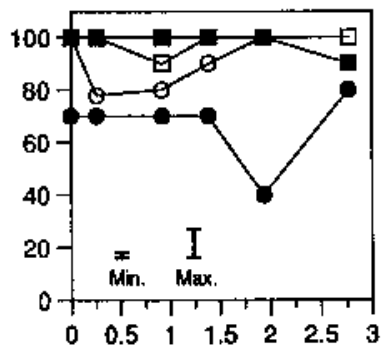

John Paul H

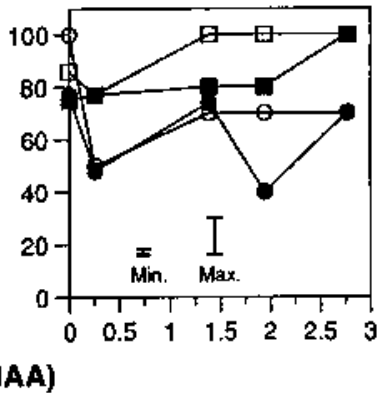

Landora

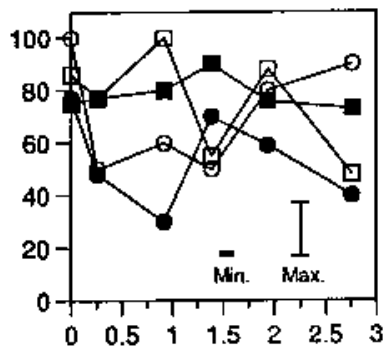

In (IAA)
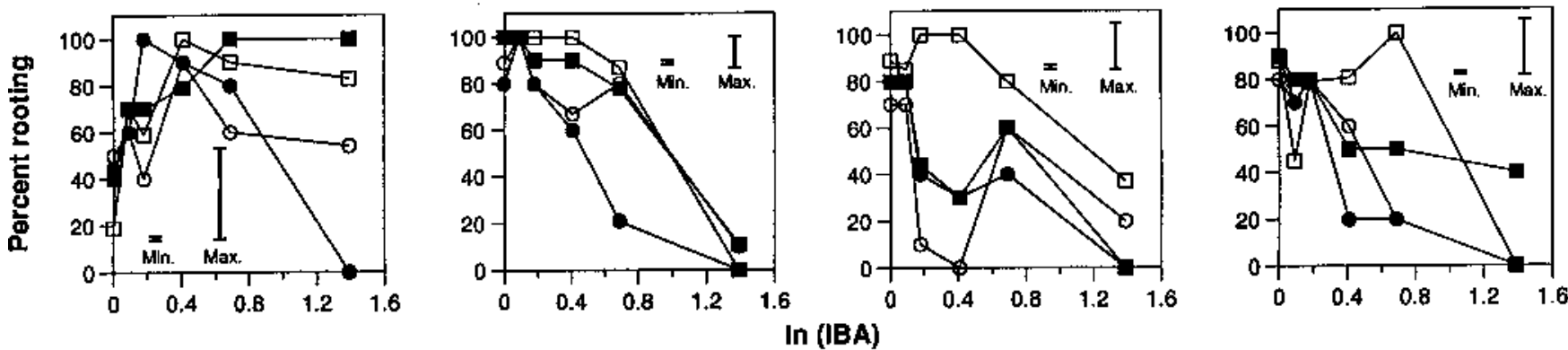

In (IBA)
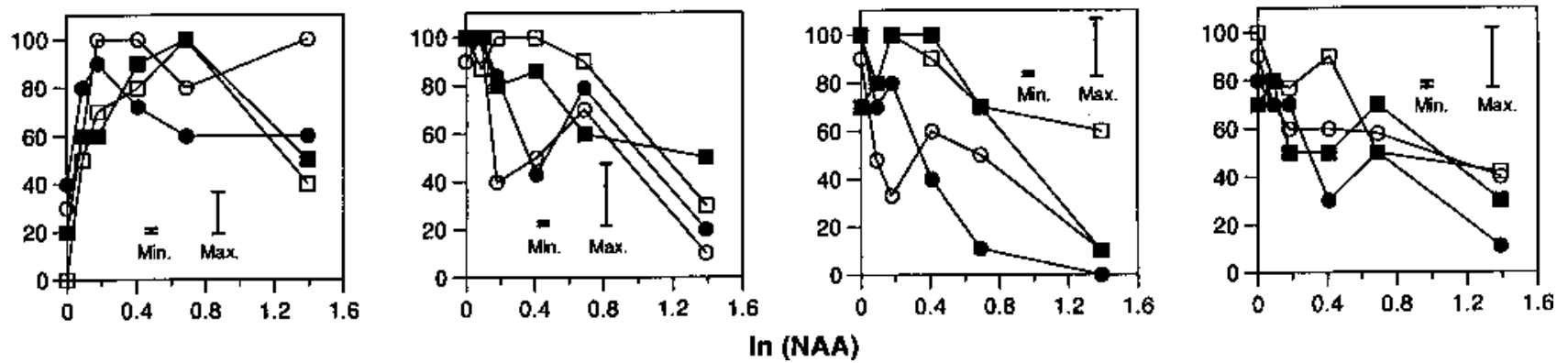

Fig. 2. Influence of auxins and medium concentrations $[(\bigcirc) 1 / 4,(\bigcirc) 1 / 2,(\square) 3 / 4$, and $(\square) 1]$ on root counts of two hardy and two hybrid tea roses. Abscissa represent natural logarithms of $(1+$ auxin concentrations $)$. Minimum and maximum sES of a mean are shown.

Average root length decreased slightly for $\ln \mathrm{C}_{\mathrm{A}} \leq 0.5 \mathrm{mg} \cdot \mathrm{liter}^{-1}$ and remained practically constant when $\mathrm{C}_{\mathrm{A}}$ was increased further (Fig. 3).

The $\mathrm{C}_{\mathrm{B}} \times \mathrm{M}$ interactions were significant for the number of roots and average root length (Table 1). Rooting percentage decreased rapidly when $\ln \mathrm{C}_{\mathrm{B}}$ was $\geq 0.2 \mathrm{mg} \cdot$ liter $^{-1}$ and approached or reached zero at high $\mathrm{C}_{\mathrm{B}}$ for all $\mathrm{M}$ (Fig. 1). The slopes of the curves for percent rooting vs. $\ln C_{B}$ were steeper for low rather than high $M$. Root counts decreased with increased $\ln C_{B}$, but $M=1$ produced 14 roots at low $\mathrm{C}_{\mathrm{B}}$ (Fig. 2). The average root length decreased with increased $C_{B}$, regardless of $M$ (Fig. 3).

The $\mathrm{C}_{\mathrm{N}} \times \mathrm{M}$ interaction was significant $(P \leq 0.05)$ only for percent rooting (Table 1$)$, which decreased for any increase in $\ln C_{N}$ for all M (Fig. 1). However, percent rooting decreased more slowly for high $\mathrm{M}$. Root counts decreased with increased $\ln \mathrm{C}_{\mathrm{N}}$ for all $\mathrm{M}$ (Fig. 2 ), and it decreased rapidly toward zero at low M. Average root length and $\ln C_{N}$ relationship was similar to that for $\ln \mathrm{C}_{\mathrm{B}}$ and root length (Fig. 3).

'John Paul II'. The $\mathrm{C}_{\mathrm{A}} \times \mathrm{M}$ interactions were significant $(P \leq 0.05)$ for root counts and average root length (Table 1). The percent rooting results were variable. At $\mathrm{M}=1$, the rooting percentage was not affected by $\mathrm{C}_{\mathrm{A}}$, but at other $\mathrm{M}$ values, rooting generally decreased (Fig. 1). Similar results were obtained for root counts; they were high for high M (Fig. 2). Average root length generally decreased with increased $\mathrm{C}_{\mathrm{A}}$, irrespective of $\mathrm{M}$. Root length increased with increased $M$ (Fig. 3).

The $\mathrm{C}_{\mathrm{B}} \times \mathrm{M}$ interaction was significant $(P \leq$ 0.01 ) only for number of roots (Table 1$)$. Rooting percentage decreased with increased $\ln C_{B}$, regardless of $M$ (Fig. 1), but it decreased more slowly at $\mathrm{M}=1$ than at any other concentration. Root counts decreased rapidly to zero with any increase in $C_{B}$, except at $M=1$, where it increased until $\ln C_{B}=0.4 \mathrm{mg} \cdot \mathrm{liter}^{-1}$ and then decreased (Fig. 2). Average root length decreased rapidly with increased $C_{B}$ for all $M$ (Fig. 3).

The $\mathrm{C}_{\mathrm{N}} \times \mathrm{M}$ interactions were highly significant $(P \leq 0.01)$ for percent rooting and root counts but were not significant for average root length (Table 1). Percent rooting decreased steeply with increased $C_{N}$ at almost all $M$ (Fig. 1). The slope of percent rooting vs. In $\mathrm{C}_{\mathrm{N}}$ was more gradual for high rather than low $\mathrm{M}$. Root counts also rapidly approached zero as $\mathrm{C}_{\mathrm{N}}$ increased (Fig. 2). Average root length decreased with increased $\mathrm{C}_{\mathrm{N}}$ for all $\mathrm{M}$ (Fig. 3).

'Landora'. The $\mathrm{C}_{\mathrm{A}} \times \mathrm{M}$ interactions were not significant for any root characteristic stud- ied (Table 1). Percent rooting was highly variable. However, rooting was more depressed at low rather than at high M (Fig. 1). Root counts remained almost constant after an initial decrease at $\ln \mathrm{C}_{\mathrm{A}}=0.3 \mathrm{mg} \cdot \mathrm{liter}^{-1}$. There were fewer roots at low rather than high M (Fig. 2). Average root length remained almost constant for all $\mathrm{C}_{\mathrm{A}}$, with a slightly higher value at high rather than low $\mathrm{M}$ (Fig. 3).

The $C_{B} \times M$ interactions were highly significant for root counts and average root length (Table 1). Percent rooting decreased with increased $\ln C_{B}$ for all $M$ (Fig. 1). Root count rapidly approached zero for $\ln \mathrm{C}_{\mathrm{B}} \geq 0.4$ mg.liter ${ }^{-1}$, except at $M=1$, for which it increased until $\ln \mathrm{C}_{\mathrm{B}}=0.8 \mathrm{mg} \cdot \mathrm{liter}^{-1}$ and then decreased toward zero (Fig. 2). The effects of $M$ and $C_{B}$ on average root length were not as pronounced as for percent rooting. Average root length decreased slowly with increased $\mathrm{C}_{\mathrm{B}}$ for all $\mathrm{M}$ (Fig. 3).

The $\mathrm{C}_{\mathrm{N}} \times \mathrm{M}$ interaction was significant $(P$ $\leq 0.05$ ) only for average root length (Table 1 ). Percent rooting decreased rapidly with increased $\ln \mathrm{C}_{\mathrm{N}}$ for all $\mathrm{M}$, but rooting was high at high $\mathrm{M}$ (Fig. 1). Root counts decreased with increased $C_{N}$ for all $M$ (Fig. 2). Average root length decreased slowly with increased $\ln C_{N}$, but at $\mathrm{M}=1 / 4$, it peaked at $1.5 \mathrm{~cm}$ for $\ln \mathrm{C}_{\mathrm{N}}=$ 0.4 mg.liter ${ }^{-1}$ (Fig. 3). 
Champleln
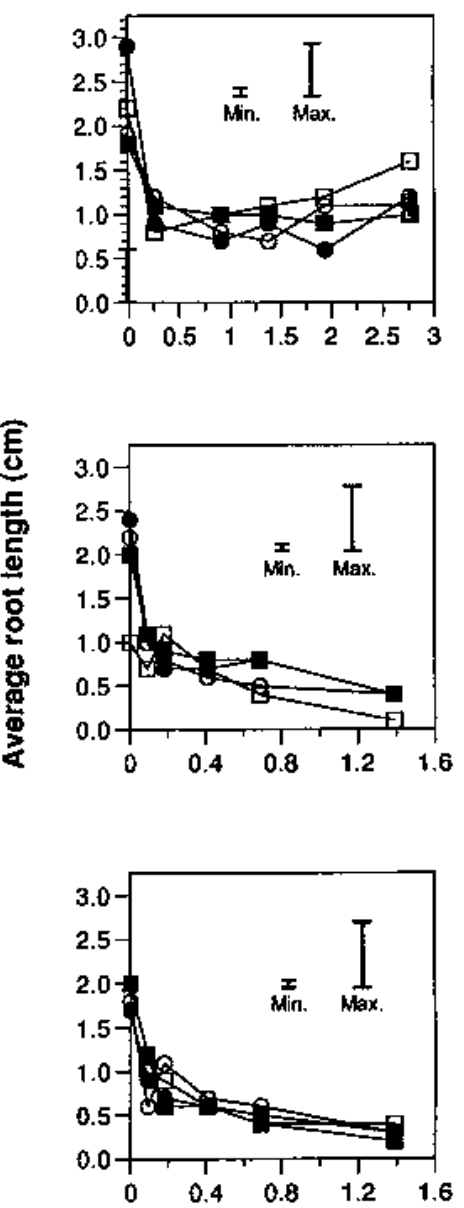

John Franklin

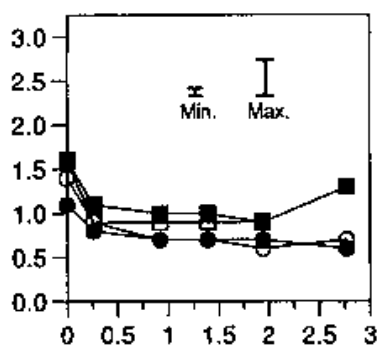

John Paul If

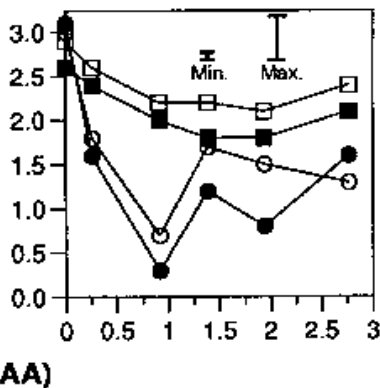

In (IAA)

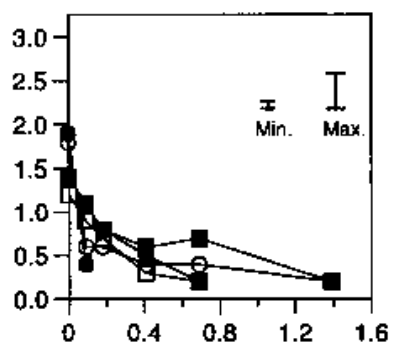

Landore

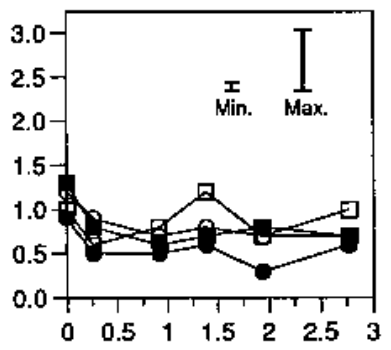

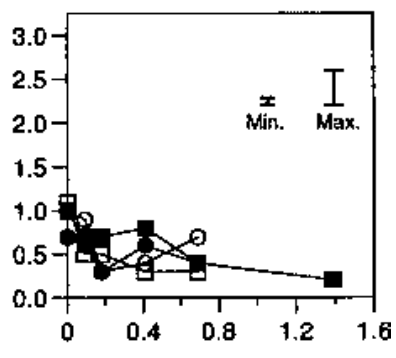

In (IBA)
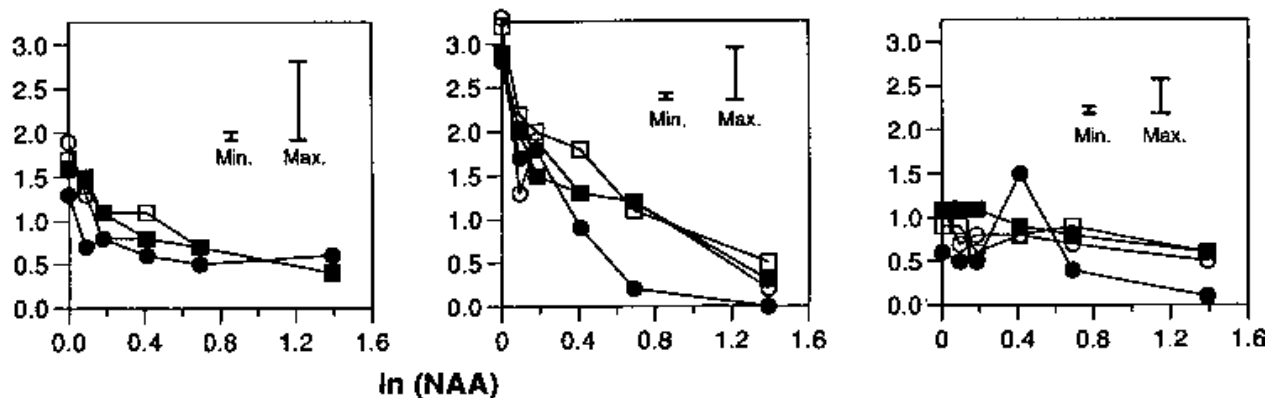

Fig. 3. Influence of auxins and medium concentrations $[(\odot) 1 / 4,(\bigcirc) 1 / 2,(\square) 3 / 4$, and $(\square) 1]$ on average root length of two hardy and two hybrid tea roses. Abscissa represent natural logarithms of $(1+$ auxin concentrations). Minimum and maximum sEs of a mean are shown.

\section{Discussion}

For each cultivar tested, rooting was $90 \%$ to $100 \%$ for at least one combination of auxin and medium salt concentrations. Generally, a high medium salt concentration produced a high percent rooting for the cultivars, and the highest percentages were obtained when IAA was included in the medium. The fullconcentration modified medium used in this study was $\approx 3 / 4 \mathrm{MS}$, and our results were similar to those reported by Skirvin and Chu (1979) and Davies (1980) for roses and those of Murashige (1979) for plants in general. Contrary to Hyndman et al. (1982), optimal rooting for 'Champlain' occurred with a high IAA concentration or within a narrow range (0.2 to 1.0 mg.liter ${ }^{-1}$ ) of IBA-NAA combinations and $\mathrm{M}$ of 0.25 to 1.0 . Our findings agree with those of Hasegawa (1980), who suggested that the difference in rooting requirements may be attributable to genotype.

We found no reports on the interactive effects of auxins and nutrient medium on the rooting of in vitro-cultured rose plantlets in the literature. However, other research indicates that IBA increased meristematic activity and advanced the formation of root initials (Samant et al., 1990), but the difference in rooting between easy and difficult-to-root pear (Pyrus communis L.) cultivars was in the uptake of IBA and its conversion to free IAA (Baraldi et al., 1993). IAA influenced the uptake of certain ions (Ilan, 1971), which affected hormones in the plant (Pearse, 1948). Although the known metabolites of NAA (Smulders et al., 1990) are different from those of IBA, their effects on nutrient absorption and their interaction may be similar. If this assumption is correct, it would explain, at least partly, the interactive effects between IBA, NAA, and M on rose genotype. However, research is needed to verify this assumption.

An average of eight or more roots per shoot developed for at least one treatment combination. The effect of $M$ was generally significant, although the increase with concentration was irregular and complicated by a significant interaction. Scotti-Campos and Pais (1990) reported that $1 / 2 \mathrm{MS}$ resulted in many roots per plant for 'Rosamini' rose. However, our results showed that the medium concentration at which we obtained the optimum root count depended on cultivar.

The maximum root count for 'John Franklin' at low to medium IBA levels was in agreement with the findings of Alderson et al. (1988). Because the highest IBA and NAA levels significantly decreased root counts for 'John Franklin', 'John Paul II', and 'Landora', these concentrations should be avoided. However, high IBA with high medium concentrations was optimal for 'Champlain'.

Although the effects of salts or auxins on rooting have been reported previously (Hasegawa, 1980), our study demonstrated that their interactive effects can significantly increase root counts depending on cultivar. The interactive effects of auxins and medium concentration influenced root count; this result needs to be confirmed by further investigations.

The average root length ranged from 0.5 to $>3 \mathrm{~cm}$, but adding any auxin to the medium reduced root length. Where the effect of increased $\mathrm{M}$ was significant, length decreased with IBA and increased with IAA and NAA. When we tested IAA, the variation in root length of 'John Paul II' was more accentuated at low than at high concentration. The significant IBA $\times$ medium interactions with 'Champlain' and 'John Franklin' were due to different root lengths at high and low concentrations at zero auxin; at high concentrations, roots were short. The significant NAA interaction with 'Landora' is attributable to a single high value at $\mathrm{M}=0.5$. 
Adding any auxin tends to reduce root length (Leopold, 1955) because growth is extremely sensitive to dilute concentrations of auxin. This effect was evident when length was significantly reduced for all cultivars with the highest IBA and NAA concentrations. As previously indicated, such concentrations should be avoided.

The interactive effects on 'John Paul II' of IAA on root length were evident between the two lower and upper values of M. Mullins (1970), and Seth and Waring (1967) reported that auxins and other growth substances in a plant can mobilize nutrients to the site of root formation. Whether a critical level of nutrients must be present to prevent mobilization from occurring is unknown, but deficiencies of macronutrients can lower the rooting response (Leopold, 1955). In addition, $\mathrm{K}$ and $\mathrm{Ca}$ also are known to affect the uptake of auxins. The interactive effects of medium and auxin concentrations were complex, and definite relationships were difficult to establish because of the genotypic differences of roses.

Recommendations in the literature for in vitro rooting of roses were based on the amount of medium salt or auxin type and their concentrations (interactive effects not shown) and were often reported for a single cultivar. However, our findings indicate that rooting response of rose cultivars to auxin or medium salt concentration is complex, and no clear relationships emerged. Thus, interactive effects between auxins and salts and plant genotype also must be considered for determining a suitable nutrient rooting medium.

\section{Literature Cited}

Alderson, P.G., J. McKinless, and R.D. Rice. 1988. Rooting of cultured rose shoots. Acta Hort. 226:175-179.

Arnold, N.P., M.R. Binns, N.N. Barthakur, and D.C. Cloutier. 1992. A study of the effect of growth regulators and time of plantlet harvest on the in vitro multiplication rate of winterhardy and hybrid tea roses. J. Hort. Sci. 67:727-735.

Baraldi, R., G. Bertazza, S. Predieri, A.M. Bregoli, and J.D. Cohen. 1993. Uptake and metabolism of indole-3-butyric acid during the in vitro rooting phase in pear cultivars (Pyrus communis). Acta Hort. 329:289-291.

Davies, D.L. 1980. Rapid propagation of roses in vitro. Scientia Hort. 13:385-389.

Genstat. 1987. Genstat 5 reference manual. National Algorithms Group, Clarendon Press, Oxford, U.K.

Hasegawa, P.M. 1980. Factors affecting shoot and root initiation from cultured rose shoot tips. J. Amer. Soc. Hort. Sci. 105:216-220.

Hyndman, S.E., P.M. Hasegawa, and R.A. Bressan. 1982. Stimulation of root initiation from cultured rose shoots through the use of reduced concentrations of mineral salts. HortScience 17:82-83.

Ilan, I. 1971. Evidence for hormonal regulation of the selectivity of ion uptake by plant cells. Physiol. Plant. 25:230-233.

Khosh-Khui, M. and K.C. Sink. 1982. Rootingenhancement of Rosa hybrida for tissue culture propagation. Scientia Hort. 17:371-376.

Leopold, A.C. 1955. Auxins and plant growth. Univ. of California Press, Los Angeles.

McCullagh, P. and J.A. Nelder. 1983. Generalized linear models. Chapman, New York.

Mullins, M.G. 1970. Hormone-directed transport of assimilates in decapitated internodes of
Phaseolus vulgaris L. Ann. Bot. 34:897-909.

Murashige, T. 1979. Principles of rapid propagation, p. 14-24. In: K.W. Hughes, R. Hanks, and M. Constantin(eds.). Propagation of higher plants through tissue culture; A bridge between research and application. National Tech. Info. Serv., U.S. Dept. of Commerce, Springfield, Va.

Murashige, T. and E. Skoog. 1962. A revised medium for rapid growth and bio-assays with tobacco tissue cultures. Physiol. Plant. 15:473-497.

Pearse, H.L. 1948. Growth substances and their practical importance in horticulture. Commonwealth Bureau of Horticulture and Plantation Crops. Tech. Comm. 20. Penglais, Aberystwyth, Great Britain.

Samant, P.K.S., D.K. Dash, H. Mishra, and P. Dae. 1990. Studies on anatomical changes during rooting in stem cuttings of Calliandra haematoxylon and Pentas carnea by application of IBA. Orissa J. Hort. 18:12-17.

Scotti-Campos, P. and M.S.S. Pais. 1990. Mass propagation of the dwarf rose cultivar 'Rosamini'. Scientia Hort. 43:321-330.

Seth, A.K. and P.F. Wareing. 1967. Hormone directed transport of metabolites and its possible role in plant senescence. J. Expt. Bot. 18:65-77.

Skirvin, R.M. and M.C. Chu. 1979. In vitro propagation of 'Forever Yours' rose. HortScience 14:608-610.

Skirvin, R.M., M.C. Chu, and J.C. Walter. 1984. Tissue culture of the rose. Amer. Rose Ann. 69:91-97.

Smulders, M.J.M., E.T.W.M. Van-de-Ven, A.F. Croes, and G.J. Wullems. 1990. Metabolism of 1-naphthaleneacetic acid in explants of tobacco: Evidence for release of free hormone from conjugates. J. Plant Growth Regulat. 9:27-34.

Valles, M. and Ph. Boxus. 1987. Micropropagation of several Rosa hybrida L. cultivars. Acta Hort. 212:611-617. 